\title{
Electrochemical Biosensor Based on Optimized Biocomposite for Organophosphorus and Carbamates Pesticides Detection
}

\author{
R. Montes, ${ }^{1}$ F. Céspedes, ${ }^{2}$ D. Gabriel, ${ }^{1}$ and M. Baeza $\mathbb{D}^{3}$ \\ ${ }^{1}$ GENOCOV Research Group, Department of Chemical, Biological and Environmental Engineering, School of Engineering, \\ Universitat Autònoma de Barcelona, Carrer de les Sitges, Bellaterra (Cerdanyola del Vallès), 08193 Barcelona, Spain \\ ${ }^{2}$ Department of Chemistry, Faculty of Science, Edifici C-Nord, Universitat Autònoma de Barcelona, \\ Carrer dels Til.lers, Bellaterra (Cerdanyola del Vallès), 08193 Barcelona, Spain \\ ${ }^{3}$ GENOCOV Research Group, Department of Chemistry, Faculty of Science, Edifici C-Nord, \\ Universitat Autònoma de Barcelona, Carrer dels Til.lers, Bellaterra (Cerdanyola del Vallès), 08193 Barcelona, Spain
}

Correspondence should be addressed to M. Baeza; mariadelmar.baeza@uab.cat

Received 21 July 2017; Revised 22 December 2017; Accepted 25 December 2017; Published 1 March 2018

Academic Editor: Mohammad Mansoob Khan

Copyright (C) 2018 R. Montes et al. This is an open access article distributed under the Creative Commons Attribution License, which permits unrestricted use, distribution, and reproduction in any medium, provided the original work is properly cited.

\begin{abstract}
This paper presents the characterization and optimization of biosensors based on graphite-epoxy which incorporates the enzyme acetylcholinesterase (AChE). By means of advanced electrochemical techniques, such as electrochemical impedance spectroscopy (EIS) and cyclic voltammetry (CV), the characterization and optimization of graphite-epoxy-AChE biosensors have been performed. In order to obtain sensitive electrodes, the optimal composition of the transducer material (graphiteepoxy-enzyme ratio) was studied. The optimization of the conductive particles distribution inside the biomaterial has allowed an improvement of the electrochemical properties. Optimal composition guarantees improving electrochemical properties required, such as high electron-transfer rate, high signal-to-noise ratio, and suitable sensitivity. The optimal biocomposite composition range was obtained between $16 \%$ and $17 \%$ of graphite and $0.12 \%$ of AChE. The biosensors were applied to the analysis of different pesticides, organophosphorus and carbamates, using indirect measurements based on enzymatic inhibition process. These optimized biosensors present detection limit one order of magnitude lower compared to the standard composition (nonoptimized) and allow achieving concentrations lower than the established ones by the pesticides regulation. Finally, spiked tap water samples with pesticides were analyzed with the optimized biosensors.
\end{abstract}

\section{Introduction}

The use of (bio)sensors applied to different fields of the analytical chemistry has been done for decades. It can be applied to clinical or medical diagnosis and food control or for environmental monitoring. Regarding the medical applications, biosensors can be used for detecting diabetes mellitus, uremia, heart failure, respiratory insufficiency, metabolic disorders, or muscle damage [1]. Biosensors have been used in environmental applications for the detection of heavy metals or other pollutants [2]. Specifically, in the literature, different biosensors applied to pesticide detection have been described [3]. Pesticides are effective against several types of pests; their long-term toxicity on human health and the ecosystem is becoming an issue at higher levels of authorities worldwide [4]. Since the first biosensor is based on acetylcholinesterase or butyrylcholinesterase in 1980 s, it has been a continuous improvement of cholinesterase based biosensors due to the gradual improvement of transducer devices and the availability of pure enzymes [5-7]. Standard procedures, based on liquid chromatography (LC) or gas chromatography (GC), are currently used for detection of wide range of pollutants with high sensitivity, reliability and precision $[8,9]$. Despite their advantages, they are expensive, requiring laboratory facilities and specialized personnel and, moreover, time-consuming and not easily adapted to field analysis [10]. Biosensors based on the inhibition of the enzyme acetylcholinesterase have been an alternative to the use of these techniques $[8,10]$. It is well known that organophosphorus and carbamate pesticides quantitatively inhibit cholinesterase. For this reason, amperometric biosensors based on inhibition of AChE have been 
extensively applied to rapid, simple, and selective analysis of pesticides (organophosphorous and carbamates) [11, 12].

A biosensor based on a biocomposite is defined as a rigid material made by combining two or more materials of different nature (phases) where at least one of them has a biological origin [20]. The overall analytical performance of the (bio)composite electrodes is strongly influenced by the carbon loading within polymeric matrix. It is due to the fact that carbon loading influences directly the electrochemical surface and inner structure (bulk resistance) of the (bio)composite electrode, which strongly affected the overall electroanalytical performance of such composite electrodes. The incorporation of a biological element inside the composite matrix produces a modification in the internal distribution of the carbon particles on both parameters (electrochemical surface and bulk resistance). Therefore, an important feature for the development of more sensitive amperometric biosensors for pesticide detection is the optimization of the biocomposite composition in order to guarantee the best final electroanalytical properties of response.

Up to now, the characterization and optimization of biosensors based on biocomposites have been done under the criteria of maximum carbon loading and maximum biological charge which provide the maximum conductivity without losing the physical and mechanical stability and the best electroanalytical signal according to the requirements, respectively [21]. However, recently, alternative strategies of characterization have been established, based on advanced electrochemical techniques, which allow improving the electroanalytical properties of the sensor electrode by means of the optimization of the biocomposite composition based on carbon materials (as conductive phase) [22, 23].

These characterization techniques are electrochemical impedance spectroscopy (EIS) and cyclic voltammetry (CV). Moreover, the viability of these techniques has been demonstrated in the characterization of composites based on different carbon allotropic forms $[24,25]$. EIS measurements provide, in an easy way, information about the electron-transfer rate, double-layer capacitance, contact resistance, and resistance of the solution (ohmic resistance) [26, 27]. The electroanalytical properties required by an electrode are high electron-transfer rate, the lowest double-layer capacitance, and ohmic resistance in order to guarantee a high signal/noise ratio, high sensitivity, and low detection limits.

The main goal of this study is the application of systematic strategies of characterization in order to optimize the biocomposite composition based on graphite-epoxy that incorporates acetylcholinesterase (AChE) on the matrix. These characterization techniques pretend to optimize the conducting particle distribution on the electrode surface as function of the carbon and biological loading. Optimized biosensors guarantee more sensitive pesticides biosensors regarding detection limits. We have constructed a series of graphiteepoxy-AChE with different graphite loadings and fixed amount of AChE. In a first stage of characterization, EIS has been used to determine the biocomposite composition which provides the best electrochemical properties. Later, these results are compared with $\mathrm{CV}$ measurements. Before the determination of pesticides, the electroanalytical response of the optimized biocomposites has been evaluated using acetylthiocholine (ATCh) as a substrate by direct amperometric measurements. Then, the optimized biosensors have been evaluated using different inhibitors, both organophosphorus and carbamates. Finally, real samples of pesticides (spiked tap water samples) have been analyzed with the optimized biosensors based on an enzymatic inhibition process of AChE.

\section{Experimental}

2.1. Chemical Reagents. Graphite powder (particle size $50 \mu \mathrm{m}$ ) was supplied by Merck (Merck Millipore, Darmstadt, Germany). Epoxy resin Epotek H77A and hardener Epotek H77B were obtained from Epoxy Technology (Epoxy Technology, Billerica, MA, USA). Potassium ferricyanide/ ferrocyanide (99.8\%), potassium chloride (99.5\%) ACS grade, potassium phosphate monobasic $(99.5 \%)$, potassium dibasicanhydrous (98\%), nitric acid (65\%), methanol for HPLC ( $\geq 99.9 \%$ ), acetylcholinesterase from Electrophorus electrics (electric eel, type VI-S, EC. 3.1.1.7, 518 units/mg solid), acetylthiocholine chloride (>99\%), Carbofuran PESTANAL, Carbaryl PESTANAL, Paraoxon-ethyl PESTANAL, Malathion PESTANAL, and Dichlorvos PESTANAL were supplied from Sigma-Aldrich (St. Louis, MO, USA) and used without further purification. All the dissolutions were prepared using deionised water from Milli-Q system (Millipore, Billerica, MA, USA).

2.2. Fabrication of the Working Electrodes. Handmade biocomposites were prepared following the conventional methodology previously established in our research group [28]. A resin Epotek $\mathrm{H} 77$ and their corresponding hardener compound were mixed in a ratio of $20: 3(\mathrm{w} / \mathrm{w})$. The graphite composite was prepared by loading different amounts of graphite $(14 \%, 15 \%, 16 \%, 17 \%$, and $20 \%(\mathrm{w} / \mathrm{w}))$ into the epoxy resin before hardening. The composite was homogenized for $30 \mathrm{~min}$. After the homogenization time, the acetylcholinesterase amount $(0.12 \%(\mathrm{w} / \mathrm{w})$ and $0.24 \%(\mathrm{w} / \mathrm{w}))$ was introduced to the composite paste and homogenized for $15 \mathrm{~min}$ more. The final biocomposite paste electrode was introduced in a PVC tube (6 mm i.d.) which has a cavity of $3 \mathrm{~mm}$ long. The electrode was allowed to harden during 5 days at $40^{\circ} \mathrm{C}$. Finally, the surface was polished with different sandpapers of decreasing grain size (800 and 1200 grits) and with alumina paper (polishing strips 948201, Orion). The final electrode dimensions were $28 \mathrm{~mm}^{2}$. When the electrodes were not in use, they were stored at $4^{\circ} \mathrm{C}$.

2.3. Apparatus. Electrochemical impedance spectroscopy and voltammetric measurements were performed using a computer controlled Autolab PGSTAT12 potentiostat/galvanostat (Eco Chemie, Utrech, The Netherlands) with a threeelectrode configuration. A platinum-based electrode 53-671 (Crison Instruments, Alella, Barcelona, Spain), an AgCl covered silver wire, and the constructed graphite biocomposite electrodes were used as a counter, reference, and working electrodes, respectively.

Amperometry measurements were done using an amperimeter LC-4C (Bioanalytical Systems Inc., West Lafayette, 
IN, USA), connected to a personal computer by data acquisition card ADC-42 Pico Technology (St. Neots, Cambridgeshire, UK) for data registering and visualization. Threeelectrode configuration was used: a single junction reference electrode Ag/AgCl Orion 900100 (Thermo Electron Corporation, Beverly, MA, USA) and platinum-based electrode were used as reference and auxiliary, respectively, and graphite biocomposites electrodes were used as working electrode. A magnetic stirrer provided the convective transport during the amperometric measurements.

\subsection{Procedure}

2.4.1. Electrochemical Characterization. EIS measurements were made in a $0.1 \mathrm{M}$ potassium chloride solution containing $0.01 \mathrm{M}$ potassium ferricyanide/ferrocyanide $\left(\mathrm{Fe}(\mathrm{CN})_{6}{ }^{3-}\right.$ / $\left.\mathrm{Fe}(\mathrm{CN})_{6}{ }^{4-}\right)$ under quiescent condition. The impedance spectra were recorded in the frequency range $0.1 \mathrm{~Hz}$ to $100 \mathrm{kHz}$ at the redox equilibrium potential. The signal amplitude to perturb the system was $10 \mathrm{mV}$. Voltammetric measurements were taken using a $0.1 \mathrm{M}$ potassium chloride solution containing $0.01 \mathrm{M}$ potassium ferricyanide/ferrocyanide $\left(\mathrm{Fe}(\mathrm{CN})_{6}{ }^{3-} / \mathrm{Fe}(\mathrm{CN})_{6}{ }^{4-}\right)$ under quiescent condition and scan rate of $10 \mathrm{mV} \cdot \mathrm{s}^{-1}$.

2.4.2. Working Potential Selection. The working potential used to perform the electroanalytical characterization was previously determined by linear-voltammetry using acetylthiocholine as a substrate and the optimized biocomposite graphite-epoxy-AChE (16\% of graphite loading). The measurements were made in $20 \mathrm{~mL}$ glass cell, at room temperature $\left(25^{\circ} \mathrm{C}\right)$ using $0.1 \mathrm{M}$ phosphate solution at $\mathrm{pH}=7.0$ as background electrolyte (prepared using $\mathrm{K}_{2} \mathrm{HPO}_{4}$ and $\mathrm{KH}_{2} \mathrm{PO}_{4}$ under quiescent condition), and three-electrode configuration as it was described before (see Apparatus Section 2.3). The spectra were recorded in the potential range $-1.0 \mathrm{~V}$ to $1.5 \mathrm{~V}$ and scan rate of $10 \mathrm{mV} \cdot \mathrm{s}^{-1}$. Firstly, an initial sweep is made without substrate and then, on the same record, different substrate concentration reaching a final concentration of $10 \mathrm{mM}$ is added.

2.4.3. Amperometric Measurements. Amperometric detection of acetylthiocholine was made under force convection by constant stirring $10 \mathrm{~mL}$ of the buffer solution $(0.1 \mathrm{M}$ phosphate solution at $\mathrm{pH}=7.0$ ) with magnetic stirring and by adding consecutive addition of the substrate solution. The working potential used was fixed at $700 \mathrm{mV}$ (versus Ag/ $\mathrm{AgCl})$.

2.4.4. Inhibition Tests. In order to obtain the inhibition plots of the different pesticides, the percentage inhibition method was followed. The procedure used was based on three steps. (a) The biosensor is placed in $10 \mathrm{~mL}$ cell glass of stirred buffered solution ( $0.1 \mathrm{M}$ phosphate buffer at $\mathrm{pH}=7.0)$. When the current of the biosensor becomes constant, a volume of acetylthiocholine solution $\left(5.5 \cdot 10^{-4} \mathrm{M}\right)$ was added. The current increases rapidly and reaches a steady state $\left(I_{\mathrm{ss}}\right)$. (b) After this experiment the same biosensor is incubated for
$15 \mathrm{~min}$ in $10 \mathrm{~mL}$ of a stirred buffer solution (0.1 M PBS at $\mathrm{pH}=7.0$ ) where is added a fixed volume of pesticide (in order to achieve the desired concentration of pesticide in the solution). (c) The incubated biosensor is washed well with the working buffer solution and then the step (a) is repeated obtaining lower steady currents $\left(I_{p}\right)$ after the addition of the substrate because of the inhibition (see Figure 3(b)). From these points, the percentage of inhibition, which corresponds to a fix concentration of pesticide, is calculated in the following way:

$$
I(\%)=\frac{\left(I_{\mathrm{ss}}-I_{p}\right)}{I_{\mathrm{ss}}} \times 100 .
$$

There are numerous relationships between the inhibition percentage and the inhibitory concentration and/or inhibition time reported on the literature. These relationships are usually characterized by linear [19], nonlinear, logarithmic $[29,30]$, or other type of equations. After these calculations, the inhibition plots, $I$ (\%) versus [pesticide] or log[pesticide], are constructed for the different pesticides evaluated (carbofuran, carbaryl, malathion, paraoxon, and dichlorvos).

Pesticide stock solutions were prepared daily in a mixture $50: 50$ of methanol: water (v/v) due to the low solubility of some pesticides in water at room temperature (carbofuran: $320 \mathrm{mg} / \mathrm{L}$, paraoxon: $24 \mathrm{mg} / \mathrm{L}$, carbaryl: $40 \mathrm{mg} / \mathrm{L}$, dichlorvos: $16000 \mathrm{mg} / \mathrm{L}$, and malathion: $145 \mathrm{mg} / \mathrm{L})$ [31].

\section{Results}

3.1. Electrochemical Impedance Measurements. The electrochemical parameters for each biocomposite electrode composition, such as ohmic resistance $\left(R_{\Omega}\right)$, charge-transfer resistance $\left(R_{\mathrm{ct}}\right)$, and double-layer capacitance $\left(C_{\mathrm{dl}}\right)$, with different graphite loading and constant amount of AChE, were evaluated by electrochemical impedance spectroscopy. These parameters were obtained by fitting the impedance spectra to a Randles circuit: $R_{\Omega} \cdot\left[C_{\mathrm{dl}} \cdot\left(R_{\mathrm{ct}} \cdot Z_{\mathrm{w}}\right)\right]$ showed in inset Figure 1(a), which is sufficiently suitable to interpret $R_{\Omega}, R_{\mathrm{ct}}$, and $C_{\mathrm{dl}}$ values.

Four compositions with variable graphite loading and fixed amount of AChE were evaluated. The interval selected for this study was $14 \%, 15 \%, 16 \%$, and $17 \%$ of graphite loading and were compared to the conventional composition of $20 \%$ of graphite loading which was used as a standard composition in previous works [32]. The amount of AChE immobilized on the matrix of the biocomposite is crucial for the pesticide determination [8]. Moreover, the quality and quantity of the enzyme immobilization will ultimately affect the performance of the biosensor in terms of sensitivity, stability, response time, and reproducibility [33]. According to the enzyme activity, the amount of AChE was initially fixed in $0.12 \%(w / w)$ for each composition. Thus, for each biocomposite electrode, the amount of AChE is 746 units which is sufficient for guaranteeing high enough analytical signals in the pesticides determination [31]. In early studies, we have reported that, biosensors with compositions below $14 \%$ of graphite loading in spite of having low double-layer capacitance values, it presented high ohmic resistance and 


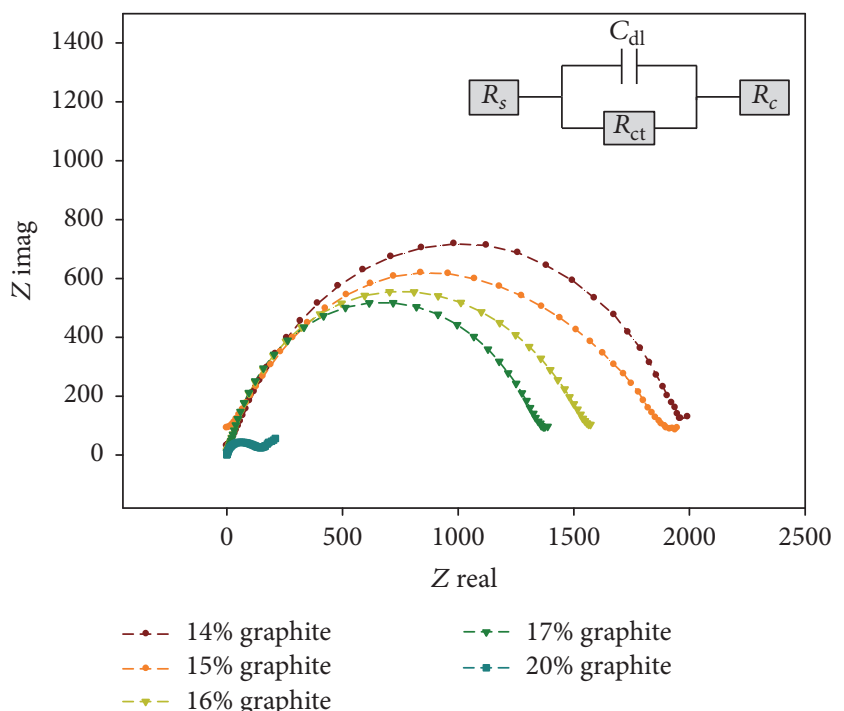

(a)

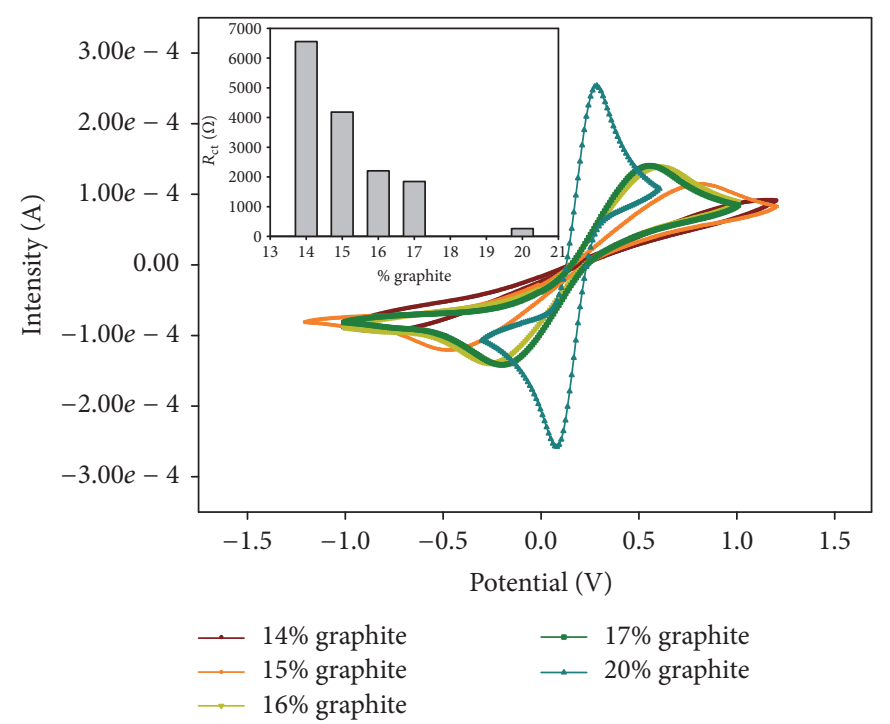

(b)

Figure 1: (a) Nyquist plots for different graphite loading electrodes with acetylcholinesterase (AChE) in presence of $0.01 \mathrm{M}$ Fe(CN) ${ }_{6}{ }^{3-}$ / $\mathrm{Fe}(\mathrm{CN})_{6}{ }^{4-}$ under quiescent condition in $0.1 \mathrm{M} \mathrm{KCl}$. The insets figure shows the equivalent circuit used for the impedance spectra fitting $\left(R_{\Omega}=R_{s}+R_{c}\right)(\mathrm{b})$ Cyclic voltammogram for biocomposites with acetylcholinesterase (AChE) using $0.01 \mathrm{M} \mathrm{Fe}(\mathrm{CN})_{6}{ }^{3-} / \mathrm{Fe}(\mathrm{CN})_{6}{ }^{4-}$ and $0.1 \mathrm{M}$ $\mathrm{KCl}$. Scan rate $10 \mathrm{mV} \cdot \mathrm{s}^{-1}$. The inset shows the trend of charge-transfer resistance for different composite composition.

charge-transfer resistance values. However, for biosensors with more than $17 \%$ of graphite loading, despite having low ohmic resistance and charge-transfer resistance values, the double-layer capacitance values increased remarkably [23]. Consequently, in the present study, this range of compositions has been not considered.

The impedance spectra recorded for each graphite composition and fixed percentage $\mathrm{AChE}$ evaluated are depicted in Figure 1(a). Nyquist plots obtained showed that compositions from $14 \%$ to $17 \%$ of graphite loading are represented by semicircle with big diameter where the impedance behaviour is dominated by kinetic process. However, for high proportions of graphite loading, $20 \%$ of graphite loading, the semicircle diameter decreases and the diffusion control start to be discerned at low frequencies (linear zone). At high carbon proportions, there is no mass transfer charge limitation on the biocomposites electrodes but the electroactive specie diffusion is limited, presenting a diffusion control (similar to macroelectrode behaviour).

The variation of the ohmic resistance as function of the graphite loading with constant amount of AChE is depicted in Figure 2(a). As it can be observed, there is a decrease on the ohmic resistance value when the graphite loading increases. This decrease on the $R_{\Omega}$ value can be associated with the increase of the conductive material present on the surface which, at the same time, increases the current conducting zones. Low values of $R_{\Omega}$ are required in order to assure good sensitivity and low response time. So, compositions between $16 \%$ and $20 \%$ of graphite loading presented the lowest ohmic resistance values.

The quantitative values of the charge-transfer resistance are shown in Figure 2(b). In general trends, a decrease on the $R_{\mathrm{ct}}$ values with the increase of the graphite loading which is proportional to the increase of the biosensor active area can be observed. In terms of charge-transfer resistance, the optimal values are presented in biocomposites compositions which presented low $R_{\mathrm{ct}}$ values. So, biocomposites between $16 \%$ and $20 \%$ of graphite loading are the ones which guarantee high electron-transfer rate and will guarantee an optimal electroanalytical response.

Finally, it is important to consider the double-layer capacitance value which is directly related to the charging or background current and inversely proportional to the signal/noise ratio. Figure 2(c) depicts the variation of this parameter as function of the graphite loading. $C_{\mathrm{dl}}$ value remains low at low graphite loading. An increase of the $C_{\mathrm{dl}}$ value is observed when the graphite loading increases to $20 \%$ of graphite loading. Based on these results and taking into the account that biocomposites with low $C_{\mathrm{dl}}$ values are the optimal in order to guarantee the minimum background current and, therefore, high signal-to-noise ratio; the biocomposites compositions between $14 \%$ and $17 \%$ of graphite loading are the ones which present low $C_{\mathrm{dl}}$ values.

According to the results obtained in the EIS characterization and taking into the account the electroanalytical properties required by a biosensor such as low response time, low limit of detection, and high sensitivity, the biocomposites between $16 \%$ and $17 \%$ of graphite loading present these requirements and, therefore, the optimal composition for their use as a transducers in analytical applications has been considered (see Supplementary Materials, Section S1). Moreover, the biocomposites composition included in this interval present similar electrochemical behaviour, so small variations in the composition inside this interval do not produce significance differences in the electrochemical properties. 


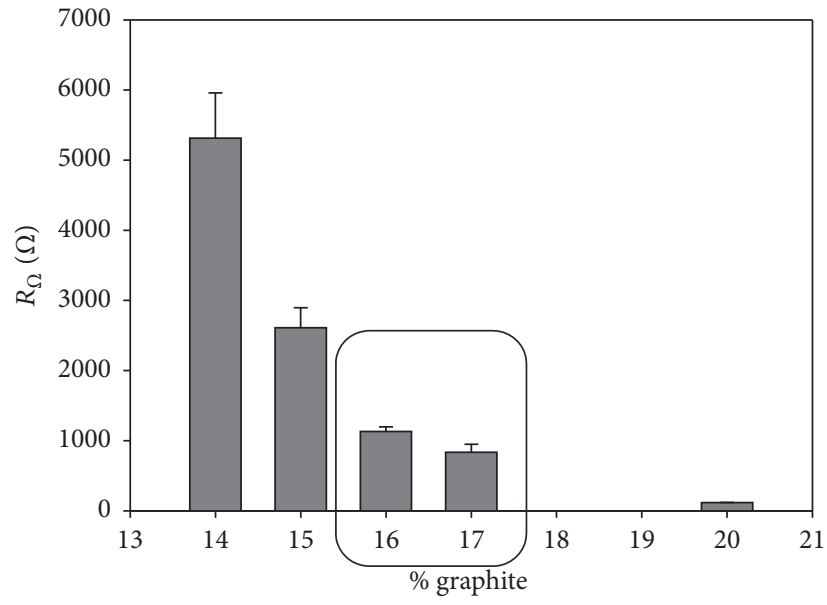

(a)

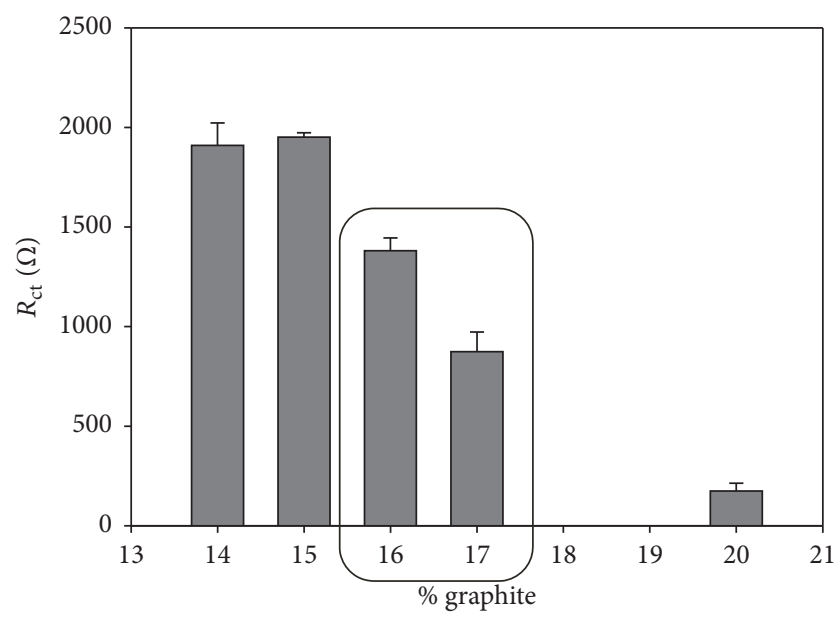

(b)

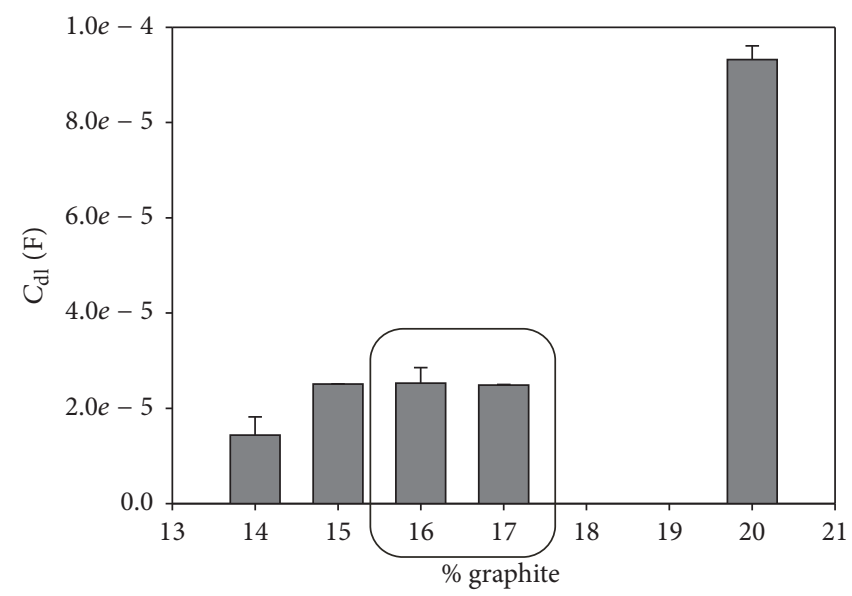

(c)

FIGURE 2: Values of (a) ohmic resistance, (b) charge-transfer resistance, and (c) double-layer capacitances, with their corresponding standard deviation $(n=3)$ for the different graphite loading electrodes with acetylcholinesterase (AChE), using the redox probe $0.01 \mathrm{M} \mathrm{Fe}(\mathrm{CN})_{6}{ }^{3-}$ / $\mathrm{Fe}(\mathrm{CN})_{6}{ }^{4-}$ and $0.1 \mathrm{M} \mathrm{KCl}$.

The results obtained showed that the incorporation of a third biological compound inside the composite matrix produces a displacement in the optimal range composition when it is compared to the graphite-epoxy composite electrodes due to the separation of the conducting particles by the presence of the enzyme charge.

\subsection{Cyclic Voltammetry Characterization. Cyclic voltamme-} try measurements were performed in order to complement EIS measurements. The different voltammograms obtained for each biocomposite composition electrodes evaluated are depicted in Figure 1(b). As it can be observed, for the biocomposite composition with $20 \%$ of graphite loading, oxidation and reduction peaks are closer to each other, and the voltammogram presents the typical macroelectrode shape where linear diffusion controls the mass transport. However, composites between $14 \%$ and $17 \%$ of graphite loading the oxidation and reduction peaks are far to each other. The cyclic voltammograms present behaviour as array of microelectrodes where the radial diffusion dominates the transport mass [34].

Different parameters can be extracted from the cyclic voltammograms such as the peak separation potential $(\Delta E)$ and peak current $\left(I_{p}\right)$ as is shown in Table 1. Furthermore, from the current intensity $\left(I_{p}\right)$ value, the electroactive area using modified Randles-Sevčik equation (see (2)) [26] can be calculated, which is appropriate for electron-transfer controlled process:

$$
I_{p}=3.01 \times 10^{5} n^{3 / 2}\left(\alpha D_{\text {red }} v\right)^{1 / 2} A C_{\text {red }}^{*}
$$

In this equation, $\alpha$ corresponds to the transfer coefficient which was considered to be approximately $0.5 ; D_{\text {red }}=6.32$. $10^{-6} \mathrm{~cm}^{2} \mathrm{~s}^{-1}$ [26] corresponds to the diffusion coefficient of the reduced species; $v=0.01 \mathrm{Vs}^{-1}$ represents the scan rate; $A$ is the electroactive area; and $C^{*}$ red $=0.01 \mathrm{M}$ is the bulk concentration of the electroactive species. As we can see in Table 1, there is an increase of the peak current with the graphite 


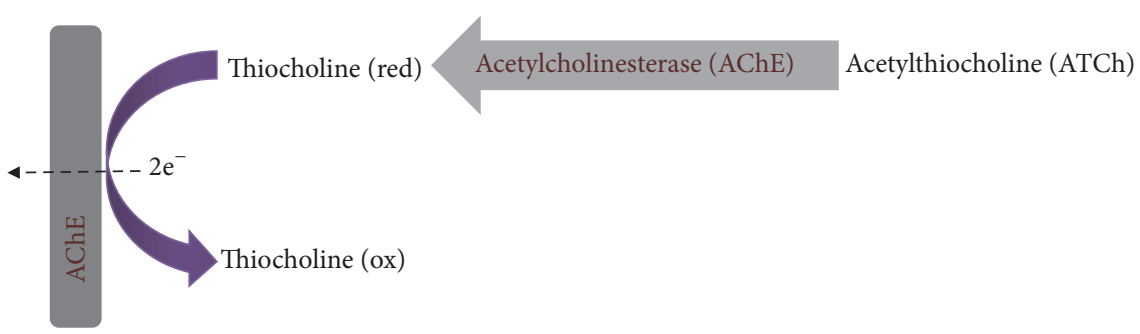

(a)

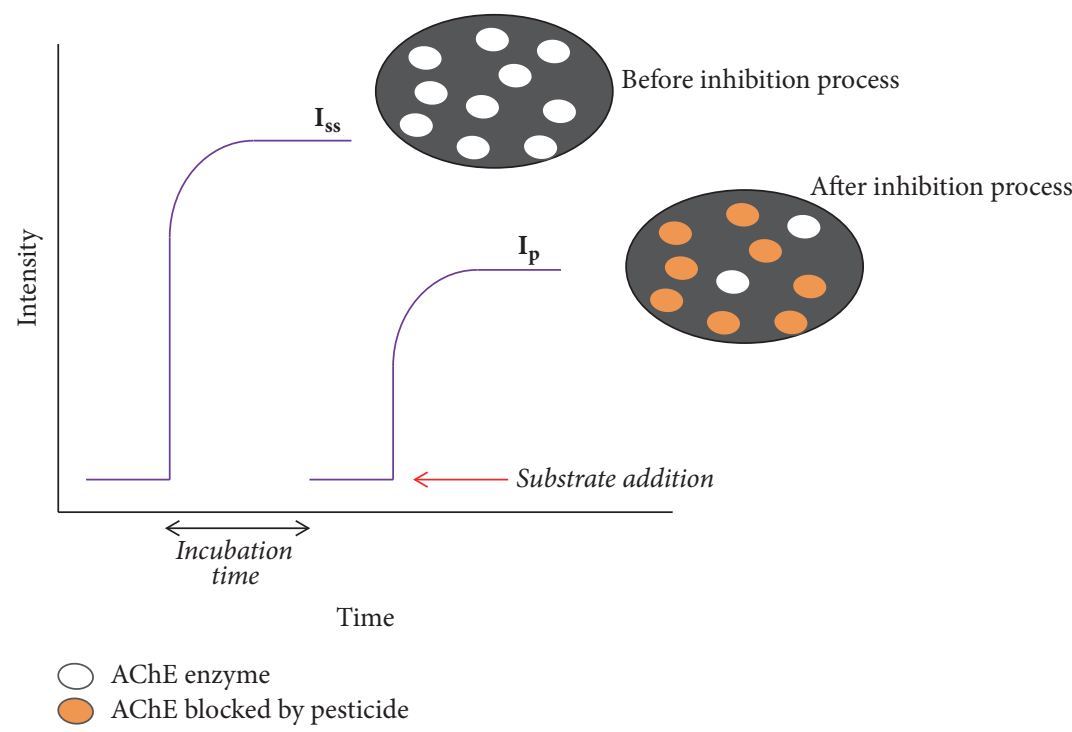

(b)

FIGURE 3: (a) Schematic representation of the enzymatic and electrochemical reactions which takes place in the biosensor surface based on biocomposite graphite-epoxy-AChE. (b) Schematic representation of the pesticides indirect determination by enzymatic inhibition. $I_{\text {ee }}$ corresponds to the maximum analytical signal of the biosensor in absence of inhibitor and $I_{p}$ corresponds to the achieved analytical signal after the previous incubation with the inhibitor.

TABLE 1: Cyclic voltammetry parameters for the different biocomposite electrode compositions of graphite/epoxy with $0.12 \%$ of AChE. $I_{o}$ corresponds to the exchange current, $R_{\mathrm{ct}}$ to the charge-transfer resistance, $I_{p}$ to peak current, $A$ to active area, and $\Delta E$ to the peak separation potential. $R_{\mathrm{ct}} \cdot A$ and $R_{\mathrm{ct}}{ }^{\mathrm{EIS}} \cdot A$ correspond to $R_{\mathrm{ct}}$ obtained by voltammetric and EIS measurements, respectively, and are normalized with respect to the active area.

\begin{tabular}{lccccccc}
\hline $\begin{array}{l}\text { Electrodes } \\
\text { \% graphite })\end{array}$ & $\begin{array}{c}i_{o} \\
(\mathrm{~A})\end{array}$ & $\begin{array}{c}R_{\mathrm{ct}} \\
(\Omega)\end{array}$ & $\begin{array}{c}I_{p} \\
(\mathrm{~A})\end{array}$ & $\begin{array}{c}A \\
\left(\mathrm{~cm}^{2}\right)\end{array}$ & $\begin{array}{c}\Delta E \\
(\mathrm{~V})\end{array}$ & $\begin{array}{c}R_{\mathrm{ct}} \cdot A \\
\left(\Omega \mathrm{cm}^{2}\right)\end{array}$ \\
\hline $14 \%$ & $3.85 \cdot 10^{-6}$ & 6557 & $9.95 \cdot 10^{-5}$ & 0.19 & 1.5678 & 1219 \\
$15 \%$ & $6.03 \cdot 10^{-6}$ & 4183 & $1.17 \cdot 10^{-4}$ & 0.22 & 1.2195 & 912 \\
$16 \%$ & $1.14 \cdot 10^{-5}$ & 2205 & $1.29 \cdot 10^{-4}$ & 0.24 & 0.7841 & 532 \\
$17 \%$ & $1.36 \cdot 10^{-5}$ & 1849 & $1.44 \cdot 10^{-4}$ & 0.27 & 0.7290 & 497 \\
$20 \%$ & $9.74 \cdot 10^{-5}$ & 259 & $2.59 \cdot 10^{-4}$ & 0.48 & 0.2078 & 353 \\
\hline
\end{tabular}

loading associated with an increase of the electroactive area, together with a decrease of the peak separation related to an enhancement of the electron-transfer rate. We also evaluate the exchange current from the Tafel plots (log current versus potential). Using the exchange current value $\left(i_{o}\right)$, we also can evaluate the charge-transfer resistance through the relation $i_{o}=R T / n F R_{\mathrm{ct}} \cdot R_{\mathrm{ct}}$ values obtained by EIS are following the same trend like the results obtained by $\mathrm{CV}$ technique (see
Figure 2(b) and inset figure in Figure 1(b)). We have normalized $R_{\mathrm{ct}}$ value obtained by both electrochemical techniques (EIS and $\mathrm{CV}$ ) with respect to the electroactive area $(A)$ (see Table 1) and it is observed that there is a decrease on the $\left(R_{\mathrm{ct}} \cdot A\right)$ and $\left(R_{\mathrm{ct}}{ }^{\mathrm{EIS}} \cdot A\right)$ values when the graphite loading increases showing the evident influence of the electrochemical anisotropy of the graphite, as a carbon material, which can be more noticeable as the graphite loading is increased. 


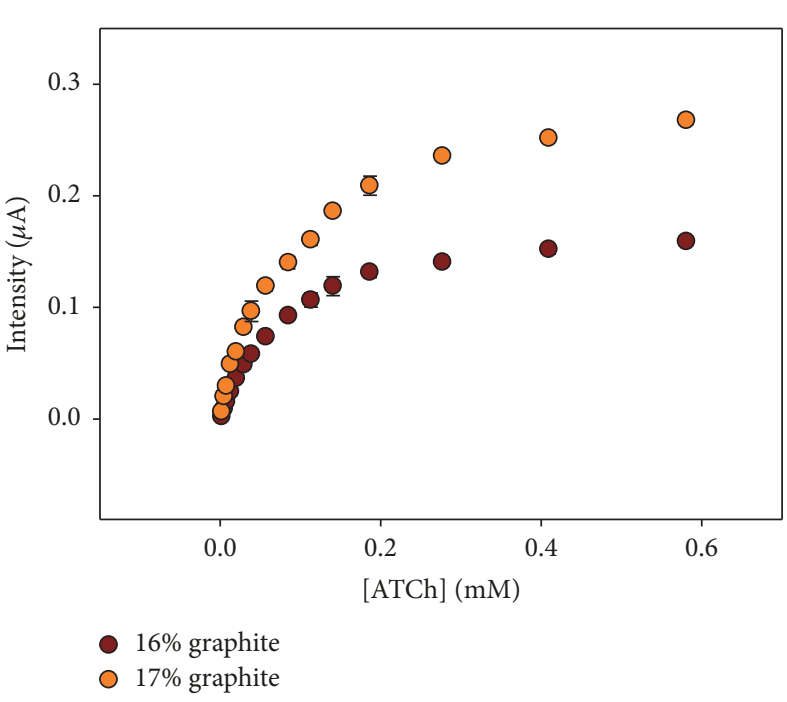

(a)

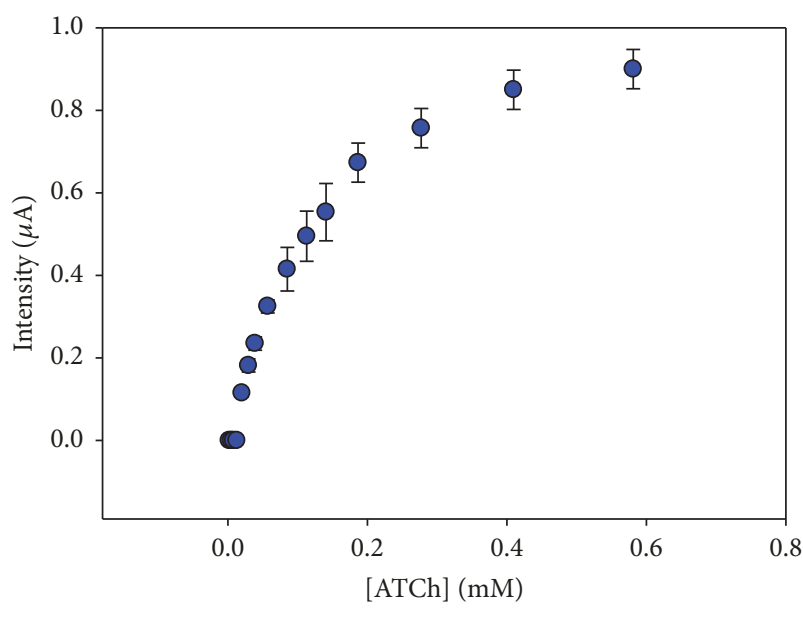

- $20 \%$ graphite

(b)

FIGURE 4: Acetylthiocholine calibration plots for biosensors with (a) 16\% and 17\% of graphite and (b) 20\% graphite loading. Measurements were carried out in $0.1 \mathrm{M}$ phosphate solution at $\mathrm{pH}=7.0$ and $0.1 \mathrm{M} \mathrm{KCl}$. EAPP $=700 \mathrm{mV}$.

\subsection{Electroanalytical Characterization}

\subsubsection{Inhibition Measurements: Indirect Pesticide Determina-} tion. Acetylthiocholine (ATCh) was used as a substrate for evaluating the electroanalytical response of the biocomposite electrodes versus pesticides inhibition. The response mechanism of the biosensor graphite-epoxy-AChE is based on two different steps. In a first step, the acetylthiocholine is biocatalytically hydrolyzed by the acetylcholinesterase enzyme producing acetic acid and thiocholine. In a second step, thiocholine is electrochemically oxidized in the electrode surface using a fixed potential (see Figure 3(a)). The current intensity generated by this oxidation is directly proportional to the ATCh concentration in solution.

Firstly, linear sweep voltammograms were performed on the graphite-epoxy-AChE biocomposites for acetylthiocholine (ATCh) in order to determine the optimum polarization potential used in the amperometric measurements (see Supplementary Materials, Section S2). The result obtained in this study shows that the plateau was obtained at $700 \mathrm{mV}$ (versus $\mathrm{Ag} / \mathrm{AgCl}$ ). So, this potential was chosen for the amperometric measurements.

In order to use the biosensors in the determination of pesticides, it is important to determine the substrate concentration range from which the enzyme begins to saturate. Under saturate conditions, the generated intensity by the biosensor is constant and independent of the substrate concentration present. In the pesticide determination by enzymatic inhibition, it is recommended to work under saturation conditions with a higher initial analytical signal in order to assure the maximum applicability of the biosensor due to the irreversible enzymatic inhibition that the AChE enzyme suffers from. In Supplementary Materials (see Section S3), the electroanalytical parameters of response of the biosensors are described regarding limit of detection, sensibility, and linear range for acetylthiocholine.
As it can be observed in Figure 4(a), for the biocomposites compositions with $16 \%-17 \%$ of graphite loading, concentrations higher than $0.4 \mathrm{mM}$ of ATCh, the analytical signal starts to be independent of the substrate concentration. For biocomposites with $20 \%$ of graphite loading (see Figure 4 (b)), the saturation zone appears for concentrations of substrate higher than $0.6 \mathrm{mM}$. An increase of the electrode electrochemical active area produces an increase on the signal current intensity generated on the surface. Therefore, according to the results obtained, pesticide inhibition determination was performed using a constant concentration of ATCh of $5.5 \cdot 10^{-4} \mathrm{M}$.

Two procedures can be followed for the detection of pesticides, the direct method, and the indirect method [35]. By means of the direct determination method, it was only possible to detect pesticide concentrations higher than $10^{-3} \mathrm{M}$. For this reason, the indirect method was followed in the present study (see Section 2.4.4). Thus, a comparative study for the biocomposite electrodes with $16 \%, 17 \%$ and $20 \%$ of graphite loading was performed.

The inhibition effect of carbofuran, carbaryl, dichlorvos, malathion, and paraoxon on the graphite-epoxy-AChE biosensor is shown in Figures $5\left(a_{1}\right), 5\left(b_{1}\right), 5\left(c_{1}\right), 5\left(d_{1}\right)$, and $5\left(e_{1}\right)$. Relationships between percentage inhibition and the inhibitory pesticide concentration can usually be characterized by linear, nonlinear, logarithmic, or other types of equation [11]. As it can be seen in Figures $5\left(a_{2}\right), 5\left(b_{2}\right), 5\left(c_{2}\right), 5\left(d_{2}\right)$, and $5\left(e_{2}\right)$, a linear relationship between inhibition percentage and $\log$ [pesticide] was obtained. The results obtained showed that biosensors with $20 \%$ graphite loading do not allow determining low inhibitor concentrations. Although inhibition occurs in the same manner in surface of all the biosensors studied (all have the same fixed amount of enzyme), the electrochemical characteristics of the biosensor with the standard composition (nonoptimized composition with 

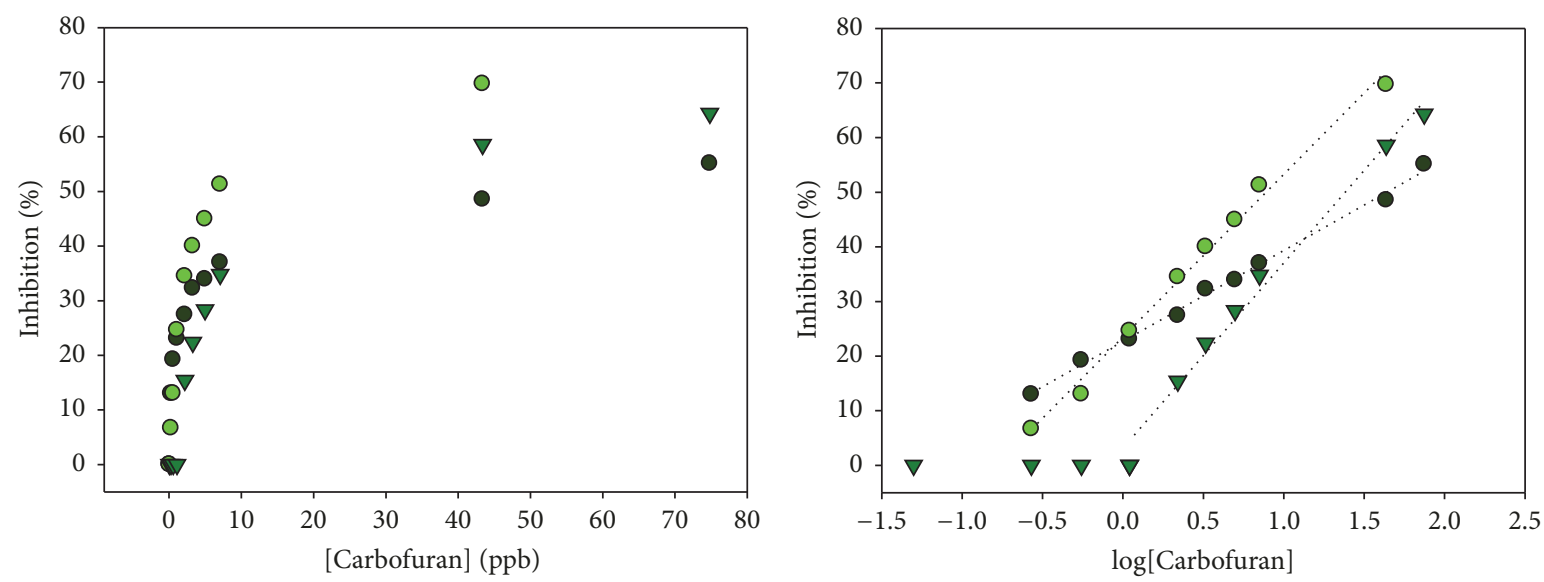

- $16 \%$ graphite

- $17 \%$ graphite

$\nabla$ 20\% graphite

- $16 \%$ graphite

- $17 \%$ graphite

$\nabla$ 20\% graphite

$\left(a_{2}\right)$

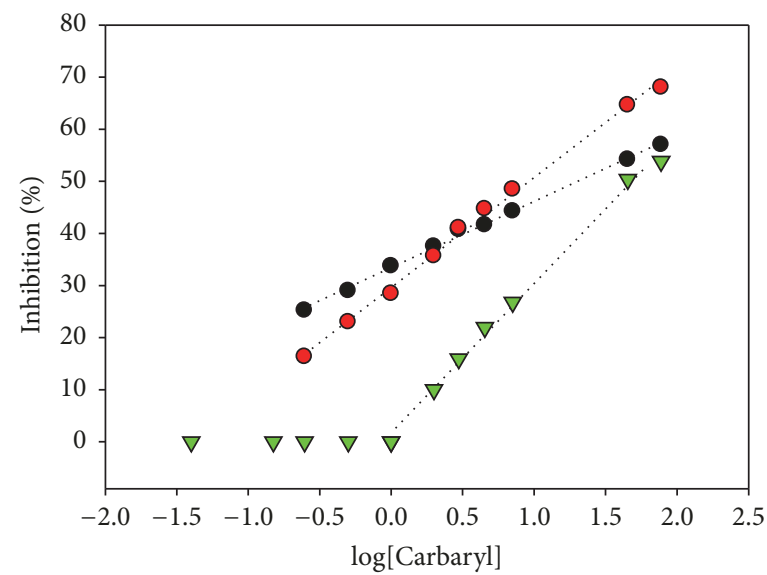

- $16 \%$ graphite

- $17 \%$ graphite

$\nabla 20 \%$ graphite

$\left(b_{2}\right)$

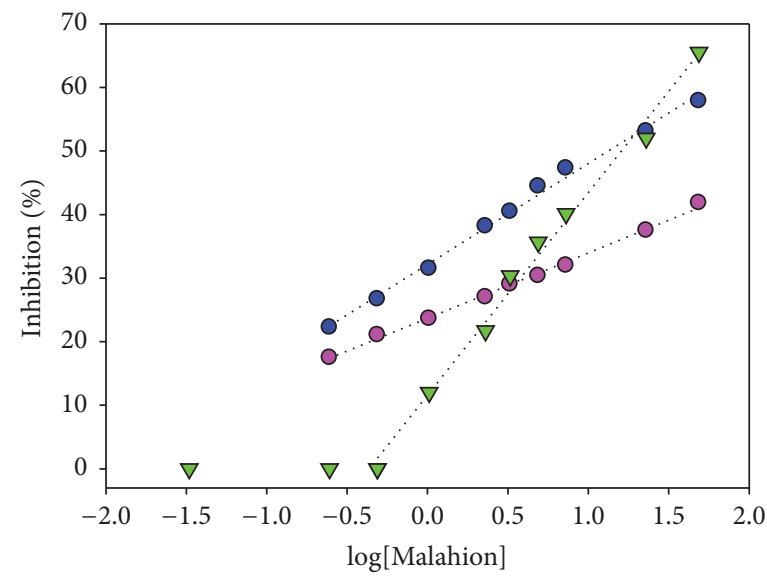

- $16 \%$ graphite

- $17 \%$ graphite

$\nabla 20 \%$ graphite

$\left(c_{1}\right)$

$\left(c_{2}\right)$

Figure 5: Continued. 

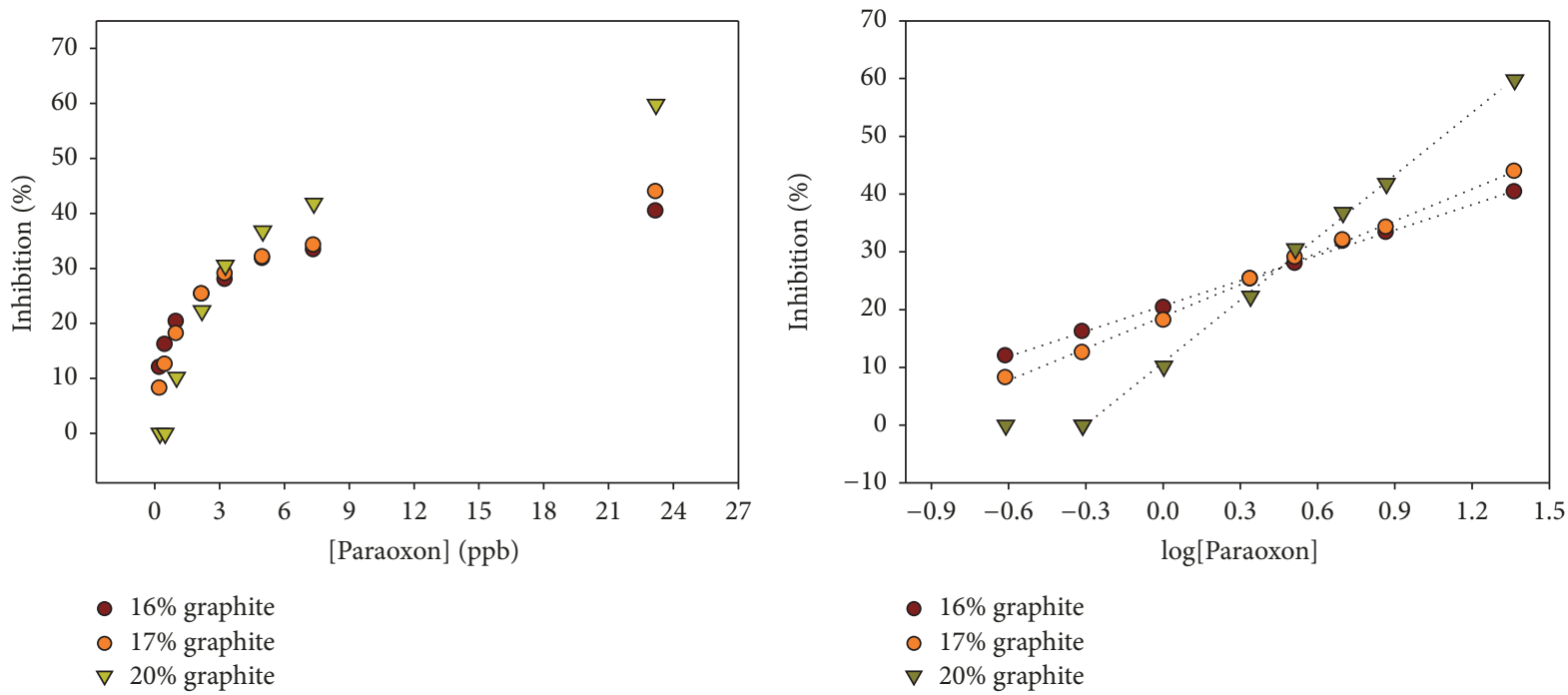

$\left(d_{1}\right)$
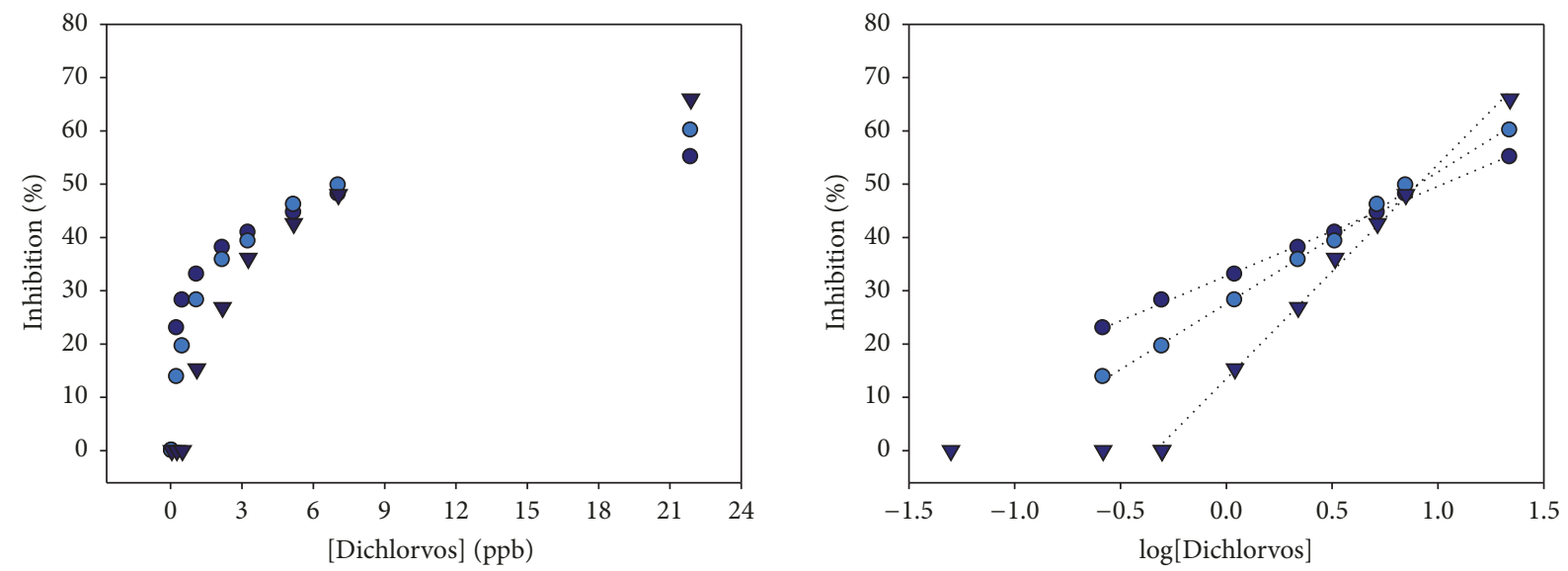

- $16 \%$ graphite

- $17 \%$ graphite

จ 20\% graphite
- $16 \%$ graphite
- $17 \%$ graphite
> $20 \%$ graphite

$\left(e_{1}\right)$

$\left(e_{2}\right)$

FIGURE 5: Direct relationship between inhibition and pesticide concentration for $\left(\mathrm{a}_{1}\right)$ carbofuran, $\left(\mathrm{b}_{1}\right)$ carbaryl, $\left(\mathrm{c}_{1}\right)$ malathion, $\left(\mathrm{d}_{1}\right)$ paraoxon, and $\left(e_{1}\right)$ dichlorvos using biosensors with $16 \%$ of graphite, $17 \%$ graphite, and $20 \%$ of graphite loading. Linear relationship between inhibition and $\log$ pesticide concentration for $\left(\mathrm{a}_{2}\right)$ carbofuran, $\left(\mathrm{b}_{2}\right)$ carbaryl, $\left(\mathrm{c}_{2}\right)$ malathion, $\left(\mathrm{d}_{2}\right)$ paraoxon, and $\left(\mathrm{e}_{2}\right)$ dichlorvos using biosensors with $16 \%$ of graphite, $17 \%$ graphite, and $20 \%$ of graphite loading. Measurements were carried out in $0.1 \mathrm{M}$ phosphate solution at $\mathrm{pH}=7.0$ and $0.1 \mathrm{M}$ $\mathrm{KCl}$ using $[\mathrm{ATCh}]=5.5 \cdot 10^{-4} \mathrm{M} . \mathrm{EAPP}=700 \mathrm{mV}$.

$20 \%$ of graphite loading) cannot distinguish small intensity variations caused by a minimum variation of the enzyme activity at low concentrations of pesticide (inhibitor). This fact is directly related to the capacity for determining smaller concentrations of enzymatic product (thiocholine) produced. However, optimized biosensors, with $16 \%$ and $17 \%$ of graphite loading, present enhanced electrochemical properties such as high signal/noise ratio values. Consequently, the detection limits achieved may significantly improve, being able to distinguish small variations in the thiocholine concentration (enzymatic reaction product) generated by the small reduction of enzyme activity (see Figure 3(a)). The enzymatic activity decrease is directly related to pesticides concentration. The limits of detection and the parameters of calibration curves for the different pesticides studied are shown in Table 2. For the optimized biosensors, it can be observed that the limit of detection achieved is one decade of concentration lower. Moreover, as it can be observed, the slope of the inhibition plots increases when the graphite loading increases. This behaviour is observed for both pesticide families, as organophosphorus and carbamates.

Regarding the biocomposites which are in the optimal composition range (16\%-17\%), there are no significant differences in the limit of detection achieved for each pesticide studied. However, biosensors with $17 \%$ of graphite loading presented better sensibility for low pesticide concentrations 
TABLE 2: Parameters obtained from the inhibition plots for the different biocomposite composition biosensors and pesticides evaluated.

\begin{tabular}{lcccc}
\hline Inhibitor & $\begin{array}{c}\text { Graphite } \\
(\%)\end{array}$ & $\begin{array}{c}\text { Slope } \\
\left.\text { (\% Inhibition } \cdot \text { decade }^{-1}\right)\end{array}$ & $\begin{array}{c}\text { Limit of detection } \\
\left(\mu \mathrm{g} \cdot \mathrm{L}^{-1}\right)\end{array}$ & $\begin{array}{c}\text { Regressioncoefficient } \\
(n=9)\end{array}$ \\
\hline \multirow{3}{*}{ Carbofuran } & 16 & $16.6 \pm 0.4$ & $0.25 \pm 0.08$ & 0.996 \\
& 17 & $30 \pm 1$ & $0.27 \pm 0.01$ & 0.992 \\
\hline \multirow{3}{*}{ Carbaryl } & 20 & $32 \pm 1$ & $2.03 \pm 0.07$ & 0.996 \\
\hline \multirow{3}{*}{ Paraoxon } & 16 & $12.7 \pm 0.3$ & $0.23 \pm 0.09$ & 0.997 \\
& 17 & $21 \pm 1$ & $0.24 \pm 0.04$ & 0.997 \\
& 20 & $27.9 \pm 0.9$ & $1.82 \pm 0.09$ & 0.996 \\
\hline \multirow{3}{*}{ Malathion } & 16 & $14.6 \pm 0.3$ & $0.25 \pm 0.03$ & 0.998 \\
& 17 & $18.4 \pm 0.4$ & $0.26 \pm 0.07$ & 0.998 \\
& 20 & $36.4 \pm 0.9$ & $0.96 \pm 0.07$ & 0.999 \\
\hline \multirow{2}{*}{ Dichlorvos } & 16 & $10.3 \pm 0.2$ & $0.25 \pm 0.03$ & 0.997 \\
& 17 & $15.7 \pm 0.5$ & $1.03 \pm 0.05$ & 0.994 \\
\hline
\end{tabular}

TABLE 3: Comparison of the analytic performance of the biosensor with few of the contemporary AChE sensors applied to the same analyte.

\begin{tabular}{|c|c|c|c|}
\hline Analyte & Electrode & Limit of detection (ppb) & Reference \\
\hline \multirow{6}{*}{ Carbofuran } & AChE/Nafion/BSA/CoPc-SPE & 0.108 & [13] \\
\hline & AChE-TCNQ/SPE & 1.1 & [11] \\
\hline & $\mathrm{AuNP} / \mathrm{AChE} / \mathrm{Au}$ & 7.26 & [14] \\
\hline & PPy-AChE-Geltn-Glut/Pt & 0.12 & [15] \\
\hline & Biocomposite $16 \%$ graphite & 0.25 & This paper \\
\hline & Biocomposite $17 \%$ graphite & 0.27 & This paper \\
\hline \multirow{7}{*}{ Paraoxon } & $\mathrm{AChE} / \mathrm{Fe}^{3+}$-BSA-Nafion & 10 & {$[16]$} \\
\hline & AChE/PAN-AuNPs/Pt & 0.739 & [17] \\
\hline & AChE/Geltn-Cellulose/SPE & 7.975 & [18] \\
\hline & AChE-Carbon Paste/Cu & 0.86 & [19] \\
\hline & PPy-AChE-Geltn-Glut/Pt & 1.1 & [15] \\
\hline & Biocomposite $16 \%$ graphite & 0.25 & This paper \\
\hline & Biocomposite $17 \%$ graphite & 0.26 & This paper \\
\hline \multirow{3}{*}{ Dichlorvos } & AChE/(MWCNTs/ALB)n/GCE & 61.87 & [5] \\
\hline & Biocomposite $16 \%$ graphite & 0.28 & This paper \\
\hline & Biocomposite $17 \%$ graphite & 0.26 & This paper \\
\hline \multirow{3}{*}{ Carbaryl } & AChE/TMOS/graphite & 2.01 & {$[3]$} \\
\hline & Biocomposite $16 \%$ graphite & 0.23 & This paper \\
\hline & Biocomposite $17 \%$ graphite & 0.24 & This paper \\
\hline \multirow{3}{*}{ Malathion } & AChE/TMOS/carbon paste & 58 & [3] \\
\hline & Biocomposite $16 \%$ graphite & 0.25 & This paper \\
\hline & Biocomposite $17 \%$ graphite & 0.24 & This paper \\
\hline
\end{tabular}

with respect to the biocomposites with $16 \%$ of graphite loading. This fact can be attributed to the improvement of the charge-transfer rate, so the biocomposite with $16 \%$ of graphite loading was more sensitive biosensor for small variations of intensity measurements.

On the other hand, performance of the fabricated biosensor has been compared with other contemporary AChE based biosensors reported in the literature. The comparison of the detection limits is shown in Table 3. As it can be observed, the limit of detection achieved for the optimized biocomposites is comparable to the others achieved with biosensors based on AChE when they are tested with the same pesticides. It is important to highlight that the optimized biosensors presented in this work have achieved lower pesticide concentration. 
TABLE 4: Results obtained in the spiked tap water samples with pesticides (carbofuran and paraoxon) using the optimized biosensors.

\begin{tabular}{|c|c|c|c|c|c|}
\hline $\begin{array}{l}\text { Pesticide } \\
\text { (inhibitor) }\end{array}$ & $\begin{array}{c}\text { Graphite } \\
(\%)\end{array}$ & $\begin{array}{c}\text { Concentration added } \\
(\mathrm{ppb})\end{array}$ & $\begin{array}{c}\text { Biosensor } \\
(\mathrm{ppb})\end{array}$ & $\begin{array}{c}\text { RDS } \\
(\%)\end{array}$ & $\begin{array}{c}\text { Recovery } \\
(\%)\end{array}$ \\
\hline \multirow{6}{*}{ Carbofuran } & \multirow{3}{*}{16} & 0.403 & $0.43 \pm 0.05$ & 12 & 107 \\
\hline & & 4.03 & $3.9 \pm 0.6$ & 15 & 101 \\
\hline & & 40.32 & $39.4 \pm 0.3$ & 1 & 98 \\
\hline & \multirow{3}{*}{17} & 0.403 & $0.42 \pm 0.03$ & 7 & 104 \\
\hline & & 4.03 & $4.0 \pm 0.1$ & 3 & 99 \\
\hline & & 40.32 & $41 \pm 2$ & 4 & 102 \\
\hline \multirow{6}{*}{ Paraoxon } & \multirow{3}{*}{16} & 0.301 & $0.30 \pm 0.01$ & 3 & 100 \\
\hline & & 3.01 & $3.2 \pm 0.1$ & 5 & 106 \\
\hline & & 30.08 & $30.8 \pm 0.1$ & 4 & 102 \\
\hline & \multirow{3}{*}{17} & 0.301 & $0.32 \pm 0.03$ & 4 & 107 \\
\hline & & 3.01 & $3.2 \pm 0.3$ & 10 & 106 \\
\hline & & 30.08 & $30.9 \pm 0.2$ & 1 & 103 \\
\hline
\end{tabular}

3.3.2. Sample Water Analysis. Analysis of carbofuran and paraoxon pesticide in tap water samples was carried out using the optimized biosensor electrodes, biocomposites with $16 \%$ $17 \%$ of graphite loading. This study has been performed in tap water samples which have been collected after a plant was watered with commercial ground and then it has been spiked with different pesticide concentrations. For these pesticides, three concentrations have been studied which include as a upper limit the legal maximum allowed by EPA [36], one intermediate concentration, and one closer to the detection limit (for each pesticide evaluated). The measurements were carried out in triplicate. The results obtained are shown in Table 4. As it can be observed, the precision obtained with this method is adequate and the recovery percentages are in all the cases near $100 \%$. Moreover, these results confirm that there is no pesticide presence in the ground susceptible to be swept along in the collected water process before the doping. So, the results obtained with the biosensor coincide with the pesticide additions made in the real samples and it is confirmed that there is no interference associated with other inhibitors.

\section{Conclusions}

Amperometric biosensors based on graphite-epoxy-AChE have been constructed, characterized, and optimized by means of EIS and CV techniques. This study has demonstrated the viability of these electrochemical techniques of characterization in the development of biosensors based on biocomposites. By means of EIS technique, the optimal composition range of conductive phase and enzyme for the biocomposite system based on graphite-epoxy-AChE that is near to a composition between $16 \%$ and $17 \%$ of graphite loading with $0.12 \%$ AChE has been estimated.

In addition, it has been demonstrated that the optimal composition allows constructing more robust amperometric biosensors based on biocomposites. Moreover, they are useful for applications that require more sensitive devices, with optimized signal-to-noise ratio, in order to determine lower analyte concentrations.
Regarding the inhibitors determination by indirect method, the optimized biocomposite sensor allows achieving lower pesticide concentrations, being these concentrations lower than the achieved ones by the standard composition electrode. Furthermore, the detection limits were lowest compared to other biosensors reported in the literature. On the other hand, in the analysis of spiked water samples with pesticides (organophosphorus and carbamates), there were no significant differences in the results obtained with the biosensors with $16 \%$ and $17 \%$ graphite loading with $0.12 \%$ AChE. In all the cases, the recovery percentage is around $100 \%$. This fact leads to the conclusion that the sample matrices did not interfere with pesticide determination and thus they were used for the analysis of spiked samples.

It is important to highlight that these electrochemical characterization strategies allow optimizing both conductive particles loading and biological material ratio present on the (bio)sensors based on rigid (bio)composites. So, after these results, it is possible to set a methodology for the composition optimization in order to improve the biosensors electroanalytical properties.

\section{Conflicts of Interest}

The authors confirm that this article content has no conflicts of interest.

\section{Acknowledgments}

R. Montes acknowledges Universitat Autònoma de Barcelona (UAB) for the award of PIF studentship. This work was supported by the research project from the Spanish Ministerio de Economía y Competitividad (MINECO), CTQ2015-69802C2-1-R.

\section{Supplementary Materials}

Supplementary information associated with this article can be found in the attached file. These data include the influence 
of the enzyme loading on the electrochemical parameters, lineal voltammetry measurements, and the electroanalytical evaluation with acetylthiocholine. Table S1: comparison of the electrochemical parameters obtained by electrochemical impedance spectroscopy $\left(R_{\Omega}, R_{\mathrm{ct}}\right.$, and $\left.C_{\mathrm{dl}}\right)$ for the biocomposites with $16 \%$ and $17 \%$ of graphite loading and $0.12 \%$ of AChE and $0.24 \%$ of AChE. Figure S1: linear sweep voltammetry response to acetylthiocholine from 0 to $10 \mathrm{mM}$ in phosphate buffer solution (PBS $0.1 \mathrm{M}$ and $\mathrm{pH}=7.0$ ). Scan rate $10 \mathrm{mV} / \mathrm{s}$. Table S2: the calibration parameters for $20 \%, 17 \%$, and $16 \%$ of graphite biocomposite electrode with $0.12 \%$ of AChE using amperometric measurements with acetylthiocholine (ATCh) as analyte and PBS $0.1 \mathrm{M}$ at $\mathrm{pH}=7.0$ as background electrolyte ( ${ }^{a} n=3,95 \%$ confidence level). Figure S2: linear response for biosensors with (A) 16\% and 17\% of graphite and (B) $20 \%$ of graphite loading. Measurements were carried out in $0.1 \mathrm{M}$ phosphate solution at $\mathrm{pH}=7.0$ and $0.1 \mathrm{M} \mathrm{KCl}$. $\mathrm{EAPP}=700 \mathrm{mV}$. (Supplementary Materials)

\section{References}

[1] A. Aparecido, P. Ferreira, C. V. Uliana, M. D. S. Castilho, N. C. Pesquero, and M. V. Foguel, "Amperometric Biosensor for Diagnosis of Disease," in State of the Art in Biosensors - Environmental and Medical Applications, T. Rinken, Ed., pp. 10-5772, doi, 10.5772/53656, 2013.

[2] L. M. D. C. Silva, V. P. S. Dos Santos, A. M. Salgado, and K. S. Pereira, "Biosensors for Contaminants Monitoring in Food and Environment for Human and Environmental Health," in State of the Art in Biosensors - Environmental and Medical Applications, pp. 151-168, 2013.

[3] N. Xia and Y. Gao, "Carbon nanostructures for development of acetylcholinesterase electrochemical biosensors for determination of pesticides," International Journal of Electrochemical Science, vol. 10, no. 1, pp. 713-724, 2015.

[4] M. M. Musameh, Y. Gao, M. Hickey, and I. L. Kyratzis, "Application of carbon nanotubes in the extraction and electrochemical detection of organophosphate pesticides: a review," Analytical Letters, vol. 45, no. 8, pp. 783-803, 2012.

[5] G. Zhao, H. Wang, and G. Liu, "Advances in biosensor-based instruments for pesticide residues rapid detection," International Journal of Electrochemical Science, vol. 10, no. 12, pp. 9790-9807, 2015.

[6] C. S. Pundir and N. Chauhan, "Acetylcholinesterase inhibitionbased biosensors for pesticide determination: a review," Analytical Biochemistry, vol. 429, no. 1, pp. 19-31, 2012.

[7] R. Ramachandran, V. Mani, S.-M. Chen, G. Gnanakumar, and M. Govindasamy, "Recent developments in electrode materials and methods for pesticide analysis - An overview," International Journal of Electrochemical Science, vol. 10, no. 1, pp. 859-869, 2015.

[8] P. Raghu, T. M. Reddy, K. Reddaiah, B. E. K. Swamy, and M. Sreedhar, "Acetylcholinesterase based biosensor for monitoring of malathion and acephate in food samples: a voltammetric study," Food Chemistry, vol. 142, pp. 188-196, 2014.

[9] S. P. Sharma, L. N. S. Tomar, J. Acharya, A. Chaturvedi, M. V. S. Suryanarayan, and R. Jain, "Acetylcholinesterase inhibitionbased biosensor for amperometric detection of Sarin using single-walled carbon nanotube-modified ferrule graphite electrode," Sensors \& Actuators: B. Chemical, Article ID 166167, pp. 616-623, 2012.
[10] J. S. Van Dyk and B. Pletschke, "Review on the use of enzymes for the detection of organochlorine, organophosphate and carbamate pesticides in the environment," Chemosphere, vol. 82, no. 3, pp. 291-307, 2011.

[11] B. Bucur, D. Fournier, A. Danet, and J.-L. Marty, "Biosensors based on highly sensitive acetylcholinesterases for enhanced carbamate insecticides detection," Analytica Chimica Acta, vol. 562, no. 1, pp. 115-121, 2006.

[12] M. Stoytcheva and R. Zlatev, "Organophosphorus Pesticides Determination by Electrochemical Biosensors," in Pesticides - Strategies for Pesticides Analysis, InTech, M. Stoytcheva, Ed., pp. 359372, 2011.

[13] S. Laschi, D. Ogończyk, I. Palchetti, and M. Mascini, "Evaluation of pesticide-induced acetylcholinesterase inhibition by means of disposable carbon-modified electrochemical biosensors," Enzyme and Microbial Technology, vol. 40, no. 3, pp. 485489, 2007.

[14] O. Shulga and J. R. Kirchhoff, "An acetylcholinesterase enzyme electrode stabilized by an electrodeposited gold nanoparticle layer," Electrochemistry Communications, vol. 9, no. 5, pp. 935940, 2007.

[15] R. Dutta and P. Puzari, "Amperometric biosensing of organophosphate and organocarbamate pesticides utilizing polypyrrole entrapped acetylcholinesterase electrode," Biosensors and Bioelectronics, vol. 52, pp. 166-172, 2014.

[16] E. Suprun, G. Evtugyn, H. Budnikov, F. Ricci, D. Moscone, and G. Palleschi, "Acetylcholinesterase sensor based on screenprinted carbon electrode modified with prussian blue," Analytical and Bioanalytical Chemistry, vol. 383, no. 4, pp. 597-604, 2005.

[17] I. Marinov, Y. Ivanov, K. Gabrovska, and T. Godjevargova, "Amperometric acetylthiocholine sensor based on acetylcholinesterase immobilized on nanostructured polymer membrane containing gold nanoparticles," Journal of Molecular Catalysis B: Enzymatic, vol. 62, no. 1, pp. 66-74, 2010.

[18] M. Pohanka, M. Hrabinova, J. Fusek et al., "Electrochemical biosensor based on acetylcholinesterase and indoxylacetate for assay of neurotoxic compounds represented by paraoxon," International Journal of Electrochemical Science, vol. 7, no. 1, pp. 50-57, 2012.

[19] D. Di Tuoro, M. Portaccio, M. Lepore et al., "An acetylcholinesterase biosensor for determination of low concentrations of Paraoxon and Dichlorvos," New Biotechnology, vol. 29, no. 1, pp. 132-138, 2011.

[20] F. Céspedes and S. Alegret, "New materials for electrochemical sensing II. Rigid carbon-polymer biocomposites," TrAC Trends in Analytical Chemistry, vol. 19, no. 4, pp. 276-285, 2000.

[21] S. Ramírez-García, S. Alegret, F. Céspedes, and R. J. Forster, "Carbon Composite Microelectrodes: Charge Percolation and Electroanalytical Performance," Analytical Chemistry, vol. 76, no. 3, pp. 503-512, 2004.

[22] R. Olivé-Monllau, M. J. Esplandiu, J. Bartrolí, M. Baeza, and F. Céspedes, "Strategies for the optimization of carbon nanotube/polymer ratio in composite materials: applications as voltammetric sensors," Sensors and Actuators B: Chemical, vol. 146, no. 1, pp. 353-360, 2010.

[23] R. Montes, J. Bartrolí, F. Céspedes, and M. Baeza, "Towards to the improvement of the analytical response in voltammetric sensors based on rigid composites," Journal of Electroanalytical Chemistry, vol. 733, pp. 69-76, 2014. 
[24] R. Montes, J. Bartrolí, M. Baeza, and F. Céspedes, "Improvement of the detection limit for biosensors: advances on the optimization of biocomposite composition," Microchemical Journal, vol. 119, pp. 66-74, 2015.

[25] J. Muñoz, J. Bartrolí, F. Céspedes, and M. Baeza, "Influence of raw carbon nanotubes diameter for the optimization of the load composition ratio in epoxy amperometric composite sensors," Journal of Materials Science, vol. 50, no. 2, pp. 652-661, 2014.

[26] M. Pacios, M. del Valle, J. Bartroli, and M. J. Esplandiu, "Electrochemical behavior of rigid carbon nanotube composite electrodes," Journal of Electroanalytical Chemistry, vol. 619-620, no. 1-2, pp. 117-124, 2008.

[27] M. J. Esplandiu, M. Pacios, L. Cyganek, J. Bartroli, and M. del Valle, "Enhancing the electrochemical response of myoglobin with carbon nanotube electrodes," Nanotechnology, vol. 20, no. 35, Article ID 355502, 2009.

[28] F. Céspedes, E. Martínez-Fàbregas, and S. Alegret, "New materials for electrochemical sensing I. Rigid conducting composites," TrAC - Trends in Analytical Chemistry, vol. 15, no. 7, pp. 296304, 1996.

[29] M. Pohanka, D. Jun, and K. Kuca, "Amperometric biosensors for real time assays of organophosphates," Sensors, vol. 8, no. 9, pp. 5303-5312, 2008.

[30] S. Zhang, Z. Gu, Y. Hu, S. Qu, and Y. Liu, "Study on the highly sensitive AChE electrode based on multiwalled carbon nanotubes," Journal of Nanomaterials, vol. 2014, Article ID 828141, 2014.

[31] Sigma Aldrich, http://www.sigmaaldrich.co, 2015.

[32] D. Martorell, F. Céspedes, E. Martínez-Fàbregas, and S. Alegret, "Amperometric determination of pesticides using a biosensor based on a polishable graphie-epoxy biocomposite," Analytica Chimica Acta, vol. 290, no. 3, pp. 343-348, 1994.

[33] Y. Gao, I. Kyratzis, R. Taylor, C. Huynh, and M. Hickey, "Immobilization of acetylcholinesterase onto carbon nanotubes utilizing streptavidin-biotin interaction for the construction of amperometric biosensors for pesticides," Analytical Letters, vol. 42, no. 16, pp. 2711-2727, 2009.

[34] J. Wang, "Practical Considerations," in Analytical Electochemistry, John Wiley \& Sons, Inc., New York, USA, 2000.

[35] S. Solé, A. Merkoçi, and S. Alegret, "Determination of toxic substances based on enzyme inhibition. Part II. Electrochemical biosensors for the determination of pesticides using flow systems," Critical Reviews in Analytical Chemistry, vol. 33, no. 2, pp. 127-143, 2003.

[36] Environmental Protection Agency (EPA), http://www.epa.gov/, 2015. 


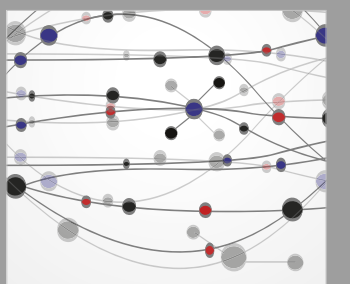

The Scientific World Journal
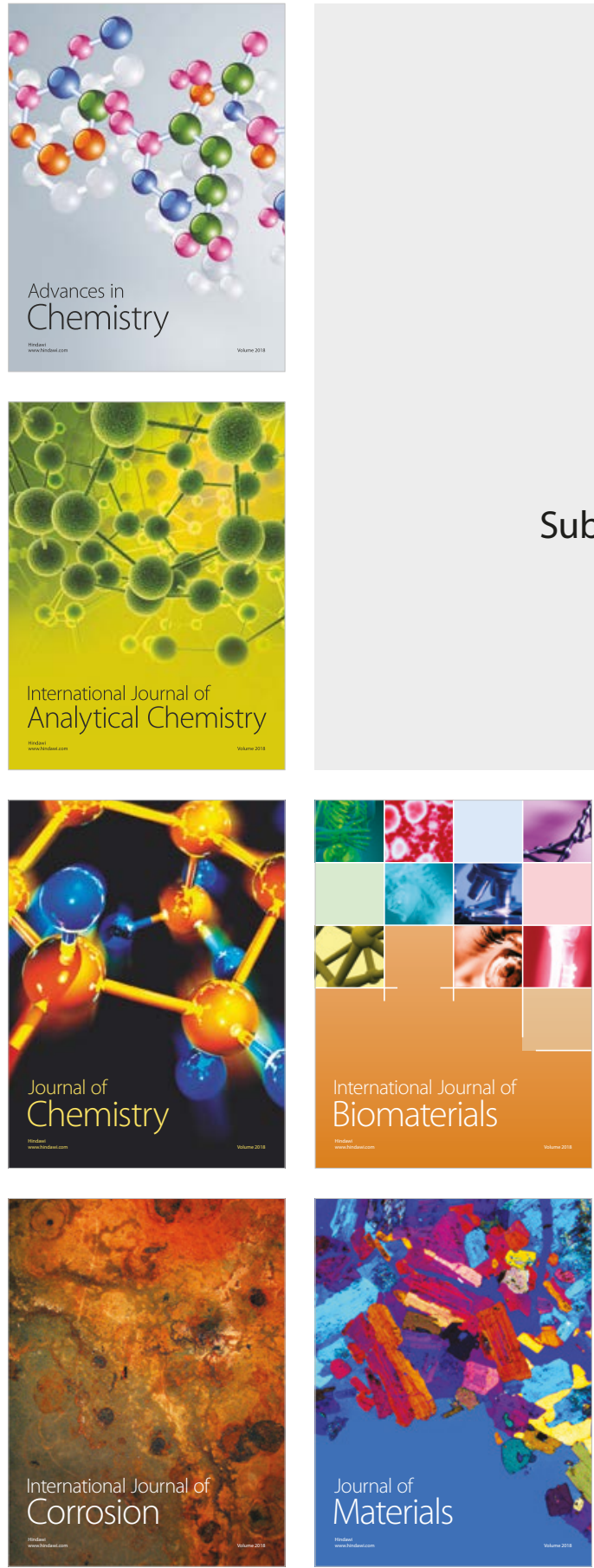

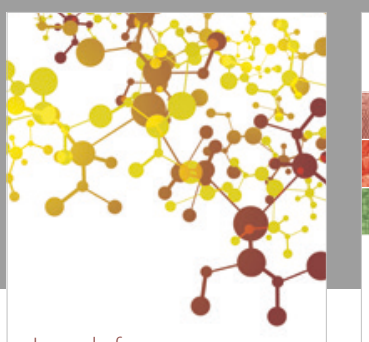

Journal of

Applied Chemistry
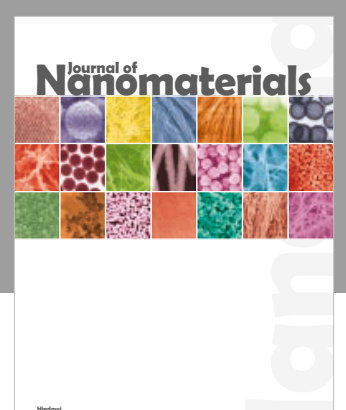

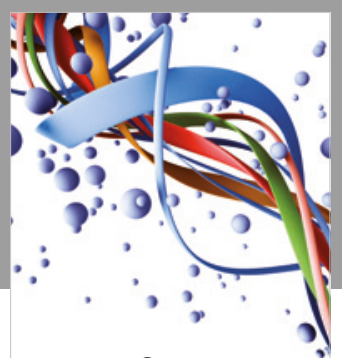

Scientifica

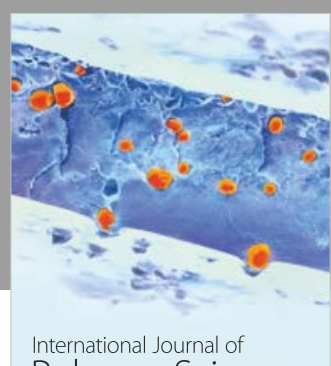

Polymer Science

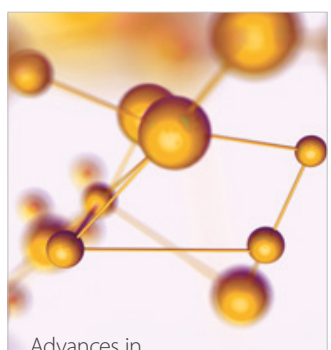

Physical Chemistry
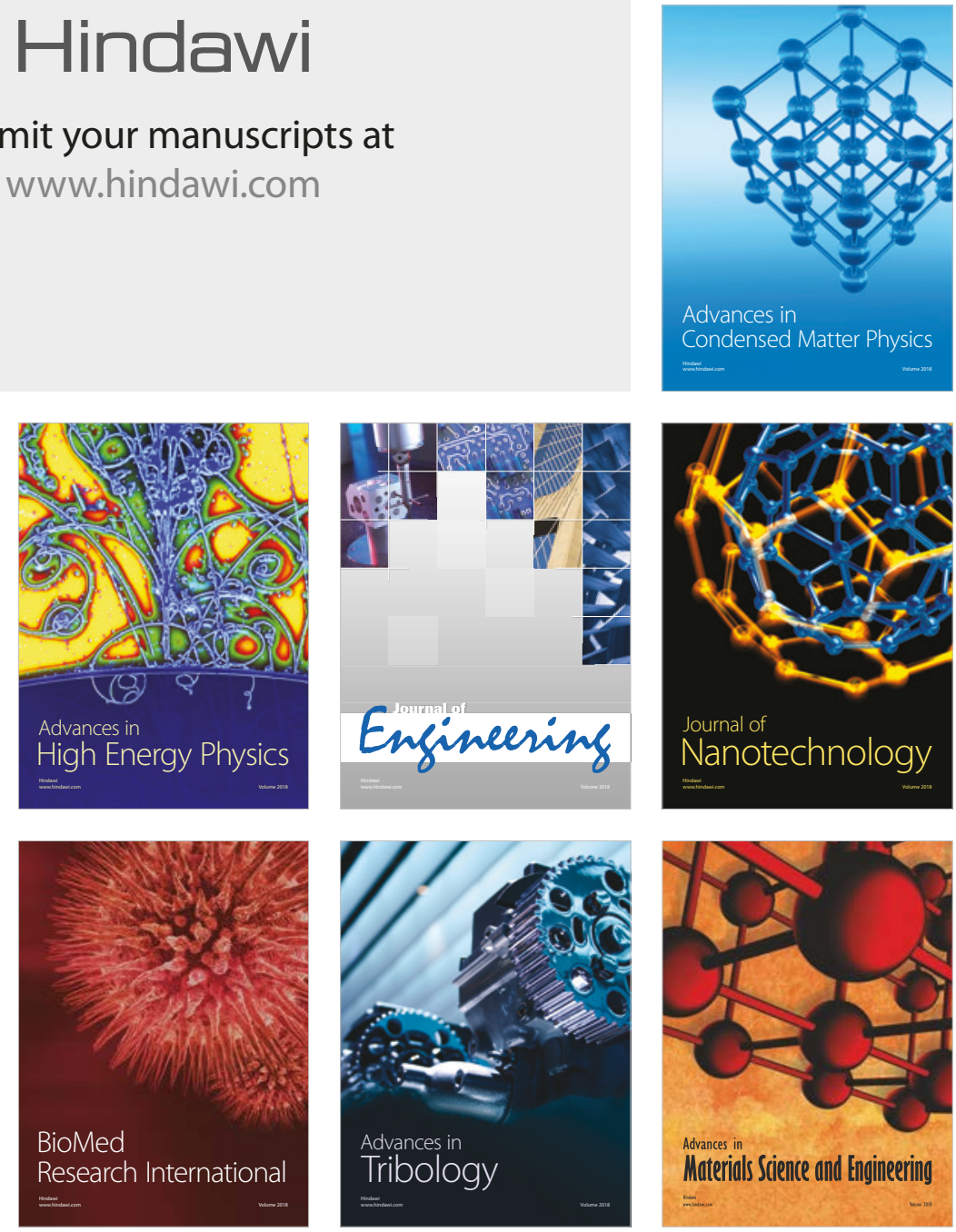